\title{
The Real Benefits of Microwave-assisted Processing Go Beyond Time Savings
}

\author{
R. T. Giberson*, M. A. Sanders**
}

*Research and Development, Ted Pella, Inc., 4595 Mountain Lakes Blvd., Redding, CA 96003

**Imaging Center Univ. of MN, 23-37 Snyder Hall, 1475 Gortner Ave., St. Paul, MN 55108

Microwave-assisted processing, from its inception, has been a methodology that promised time savings over conventional processing methods [1]. It has taken a number of years since the mid 1990's to define and develop control of the variables associated with microwave processing. There are 3 important components to consistent results that have been elucidated through research and controlled with technological advancements [2-5]. Stated simply they are: 1) the development of a device to provide energy uniformity in the microwave cavity [2-3], 2) the creation of a true wattage microwave device (continuous power over a range or wattages) [2-5], 3) independent sample temperature control in conjunction with continuous microwave radiation [3-4].

While the precise method of activation that microwave radiation contributes to accelerating a wide range of processing applications is unknown the control of microwave-assisted sample heating and magnetron wattage are now routine. The role of sample temperature in the following applications is better understood: tissue processing for electron microscopy [2], immunolabeling [3], formaldehyde fixation [4] and decalcification [5]. The importance of true wattage and a uniform microwave environment to all four applications has been demonstrated experimentally [2-5].

Recent work has shown, concurrent with time savings, improved results over conventional methods when microwave-assisted fixation is incorporated into a protocol [4]. The results clearly demonstrate that a 20 minute microwave-assisted formaldehyde fixation relying on temperature control, true wattage and a uniform microwave environment produce ultrastructural detail not attainable with a 3-hour immersion fix (Fig. 1).

Recently submitted research defines the fixation benefit further. HeLa cells were transfected with Cellular Lights Tubulin-GFP (Invitrogen, Carlesbad, CA) and 3 days later formaldehyde fixed for 1 minute at $150 \mathrm{~W}$ true wattage, labeled with mouse anti-GFP followed by Alexa 488-goat anti-mouse IgG (Invitrogen, Carlesbad, CA). The results were contrasted with identical cells conventionally fixed for 30 minutes (Fig. 2).

The two figures clearly demonstrate that accelerated fixation times (over 30-fold quicker than conventional methods) under a controlled microwave processing environment result in significant time savings concurrent with excellent processing results.

\section{References}

[1] C. P. Mayers, J Clin Pathol. (1970) 23.

[2] R. T. Giberson et al., Ultrastruct Pathol (2003) 27.

[3] T. E. Munoz et al., J Neurosci Methods (2004) 137.

[4] J. J. Galvez et al., The J Histotechnol (2006) 29.

[5] S. P. Tinling et al., J. Microsc (2004) 215. 

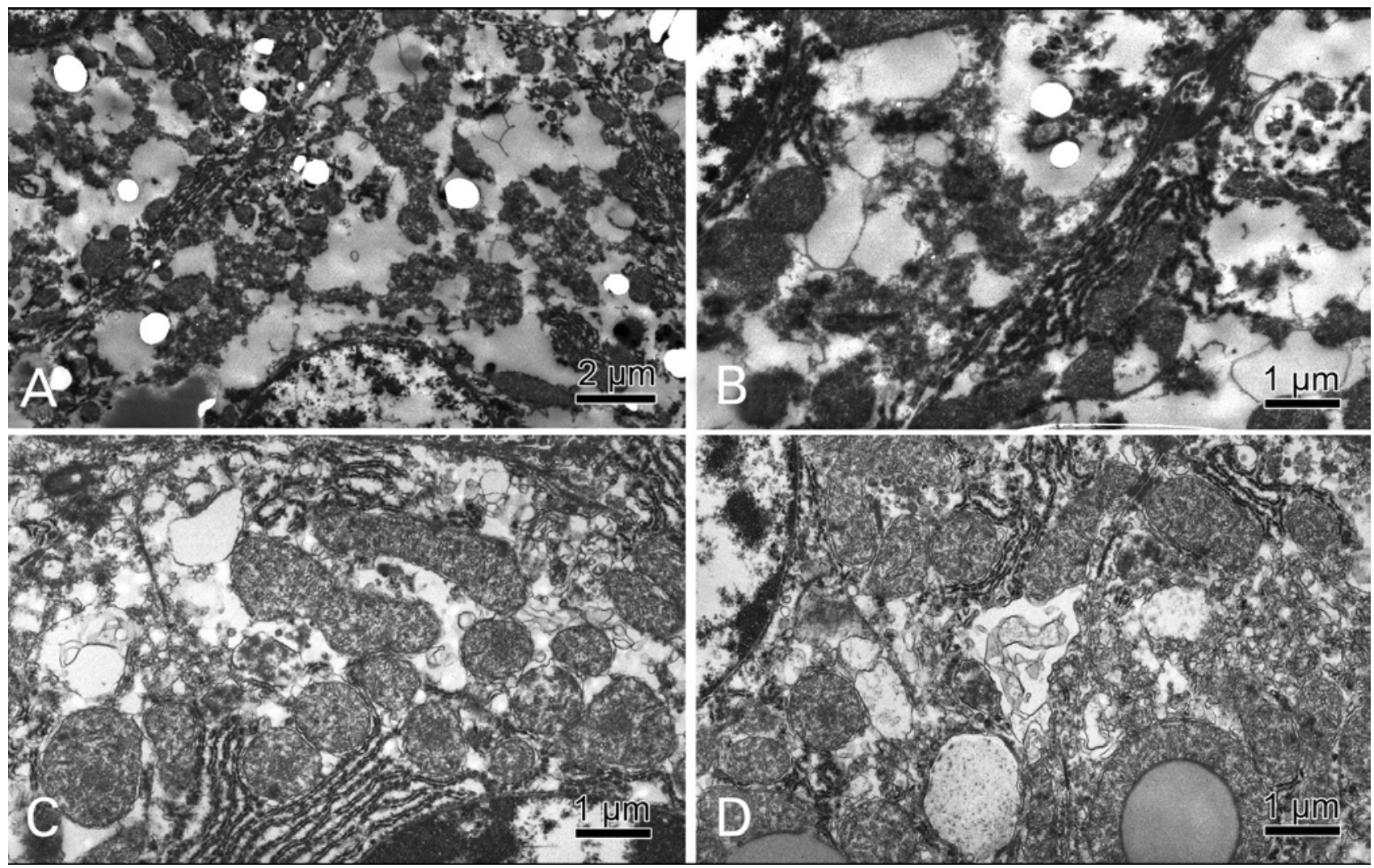

Fig. 1. Electron micrographs of ovine liver fixed in 10\% neutral buffered formalin (10\% NBF) by conventional and microwave methods. A-B. Tissues fixed conventionally for 3 hours. Note the extraction and absence of organelles. C-D. Tissues fixed with microwave radiation [4]. Note the greatly improved ultrastructure.
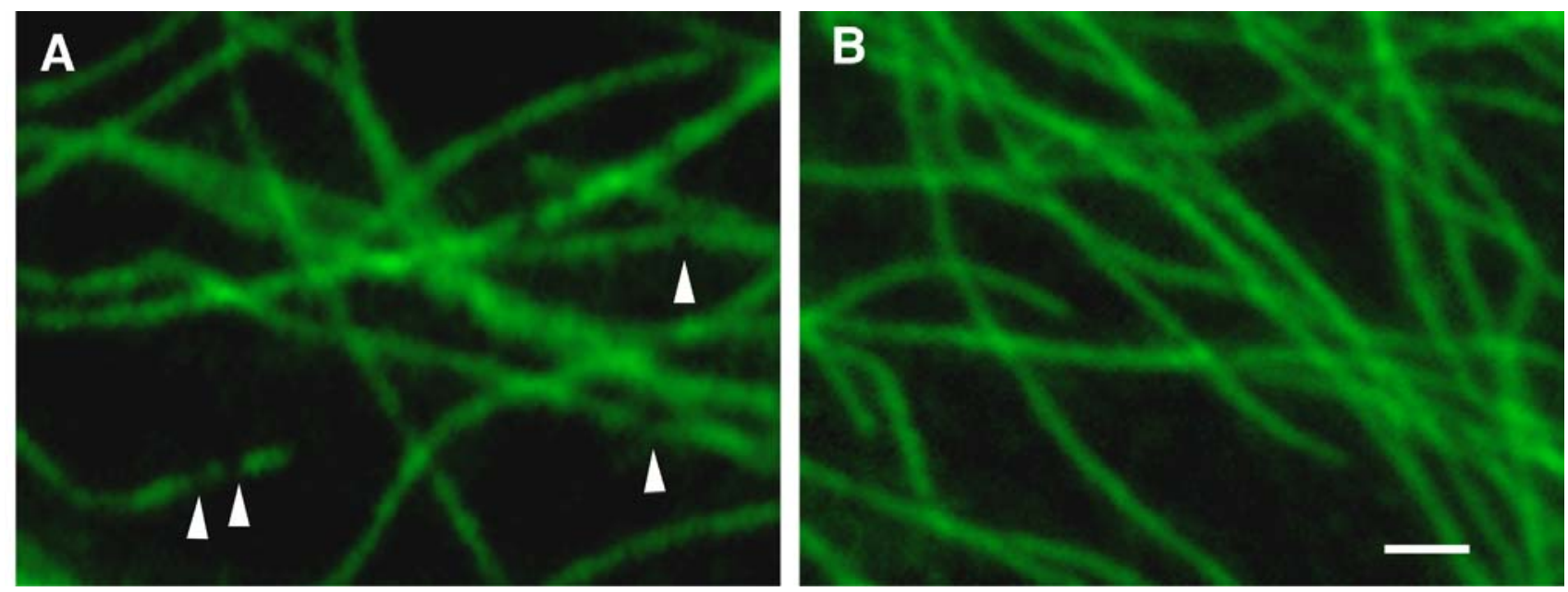

Fig. 2. HeLa cells transfected with CellularLights, tubulin GFP (Invitrogen, Carlesbad, CA) fixed in $3 \%$ formaldehyde and the labeled with an anti-GFP antibody followed by Alexa 488. A. Cells fixed conventionally for $30 \mathrm{~min}$. at 37C. The continuity of label down the microtubules is not uniform (arrows). B. Transfected Hela cells fixed in the presence of $150 \mathrm{~W}$ of microwave radiation for $1 \mathrm{~min}$. at $37 \mathrm{C}$. The continuity of the label is superior to A above. Bar $=2$ microns. 